Working Paper No. 621, 2004

\title{
Do Mergers Result in Collusion?
}

by Mattias Ganslandt and Pehr-Johan Norbäck

IUI, The Research Institute of Industrial Economics

P.O. Box 5501

SE-114 85 Stockholm

Sweden 


\title{
Do Mergers Result in Collusion?*
}

\author{
Mattias Ganslandt** \\ and \\ Pehr-Johan Norbäck***
}

June 14, 2004

\begin{abstract}
We examine coordinated effects of mergers in the Swedish retail market for gasoline during the period 1986-2002. Despite significant changes in market concentration and many factors conducive to coordination, the empirical analysis shows that the level of coordination is low. In addition, statistical tests reject the hypothesis that mergers and acquisitions result in "coordinated effects". In particular, higher market concentration does not result in more collusive behavior and, consequently, the relevance of simple "checklists" in merger control can be questioned.

Keywords: Merger control, Collusion, Coordinated effects, Oligopolistic dominance, Competition Policy

* Special thanks to Gulay Özcan for excellent research assistance and to Richard Friberg for several valuable suggestions. We are grateful for comments from seminar participants at University of Colorado at Boulder, Lund University, FIEF, IUI, Stockholm University and the Workshop on Competition Policy 2004. Financial support from Jan Wallander's and Tom Hedelius' Foundation is gratefully acknowledged. Ganslandt worked as an economic expert for Norsk Hydro in case Case T-9902-00 The Swedish Competition Authority ./. Norsk Hydro. ** Corresponding author: IUI (The Research Institute of Industrial Economics), P.O. Box 5501, SE-11485 Stockholm, Sweden e-mail mattias.ganslandt@iui.se
\end{abstract}

*** IUI, P.O. Box 5501, SE-11485 Stockholm, Sweden e-mail pjn@iui.se 


\section{Introduction}

The main objective of modern merger policy, in North America as well as in the European Union, is to control - i.e. block or clear with conditions - mergers and acquisitions that otherwise would result in anti-competitive effects. The theoretical rationale for this policy is that market concentration has an effect on firms' ability to exercise market power in a way that harm consumers. More precisely, a merger of competitors could give the newly formed entity a unilateral incentive to raise its price above the pre-merger level and, alternatively, reduce the costs and difficulties in reaching a tacit or explicit agreement bewteen the remaining competitors. These two categories are commonly referred to as "unilateral" and "coordinated" effects.

The latter of these categories, i.e. the risk of collusion, has been at the core of American merger control for years. For instance, in 1986, the influential judge and scholar Richard Posner declared that the "ultimate issue" in US merger control is to determine whether a transaction "is likely to hurt consumers, as by making it easier for the firms in a market to collude, expressively or tacitly". ${ }^{1}$ In recent years, US antitrust authorities have shown a new interest in how the agencies should analyze and prove coordinated effects in merger cases (see, for instance, James, 2002 and Kolasky, 2002).

Correspondingly, in European merger control coordinated effects theories (or, in the terminology of European merger control, "collective dominance") have grown more important, as is manifested in, for instance, the European horizontal merger guidelines (2004). ${ }^{2}$ Since the Nestlé/Perrier ${ }^{3}$ case in 1994, mergers have more frequently been challenged on the basis that they might significantly impede competition in the European market due to coordinated effects. ${ }^{4}$

Given the policy relevance and wide application of coordinated effects theories in merger

\footnotetext{
${ }^{1}$ Hospital Corp of America v. FTC, 807 F.2d 1381, 1386 (7th Cir. 1986).

2 "Guidelines on the assessment of horizontal mergers" (2004), available at DG Competition's web-page http://europa.eu.int/comm/competition/.

${ }^{3}$ M.190 - Nestlé/Perrier, Official Journal L 356 , 05/12/1992 p. 0001-0031

4 Important cases include Kali\&Salz (M. 308), Gencor/Lonhro (M. 619) and Airtours/First Choice (M. 1524).
} 
control, both in the USA and the EU, it is somewhat surprising that very few studies try to empirically evaluate the coordinated effects of mergers. ${ }^{5}$ This paper is an attempt at (partly) filling this gap by examining collusion and coordination in the Swedish gasoline retail market during the period 1986-2002.

We first estimate a variety of demand specifications and compute the price-elasticity of demand (cf. Geneovese and Mullin, 1998). Then, using a precise measure of the lower bound of the marginal cost (taxes plus the spotmarket price for premium gasoline), we compute an upper bound of the Lerner index. Proceeding in several steps, an initial analysis examines conduct by investigating the correlation between the Lerner index and price elasticity, contrasting periods without and with significant merger activity. Then, by directly measuring conduct as the elasticity-adjusted Lerner index, we proceed to directly estimating the relationship between conduct and concentration, using the time-series variation of conduct to examine coordinated effects of four significant mergers and one important divestiture during the period 1993-1999. ${ }^{6}$

More specifically, we estimate a non-linear relationship between conduct and HHI (i.e. the Hirschman-Herfindahl index) and explicitly test if an increase in concentration results in more accommodating output responses by competitors in the post-merger market. From theory, we show the latter to be equivalent to testing if the elasticity of market conduct with respect to the Hirschman-Herfindahl index exceeds unity. Finally, we also estimate the post-merger effects on a case-by-case basis to assess the relevance of additional - possibly unobserved - factors.

The empirical approach in this paper differs significantly from the technique used by antitrust agencies to assess collusion and coordinated effects in merger cases. The conventional approach to coordinated effects has been to check whether the market meets the necessary conditions for tacit or express collusion (Europe Economics, 2001). For instance,

\footnotetext{
${ }^{5}$ Coleman, Meyer and Scheffman (2003) is an interesting exception. They describe how the FTC assessed coordinated effects in the cruise ships merger investigation.

${ }^{6}$ The five transactions are: Statoil's acquisition of British Petroleum in 1993, OK Petroleum's acquisition of Texaco in 1994, OK Petroleum's dissolution into OK and Preem in 1995, Norsk Hydro's acquisition of Uno-X in 1996 and, finally, the merger between OK and Kuwait in 1999.
} 
the European Commission considers a number of factors in its assessment of coordinated effects and collective dominance, including price and cost transparency, low rate of innovation and technological development, inelastic and stable demand, market maturity, product and firm homogeneity, similar cost structures, symmetric market shares, structural links and multi-market contact (see the European Commission's contribution to the OECD round table on "Oligopoly", 1999)..$^{7}$ In addition, American as well as European antitrust agencies consider increased concentration to be important in facilitating collusion (see, for instance, the US contribution to the OECD roundtable, 1999, p 204).

In recent years, scholars - as well as practitioners - have suggested that the risk of collusion might increase as a result of a merger due to other changes than increased concentration. Baker (2002) argues that antitrust authorities should put particular focus on the analysis of maverick firms. He suggests that a merger removing a maverick could increase the risk of collusion, while it may be reduced by a transaction creating a maverick. Sheffman and Coleman (2003) and Dick (2002) add that a merger can make collusion more likely, perfect or complete by creating a market leader, making the market more transparent, limiting innovation or making suppliers, products and costs more symmetric. ${ }^{8}$

Considering the factors that have been regarded as conducive to collusion according to the traditional approach and modern theoretical analysis of collusion, we would argue the Swedish gasoline retail market to be a good natural laboratory. Initially, it may be noted that from a policy perspective, mergers in gasoline markets have been of great interest to antitrust authorities. ${ }^{9}$ More importantly, from an empirical perspective, it is indeed a

\footnotetext{
${ }^{7}$ A recent survey of US merger cases by William Kolasky (2002) shows that US authorities use a similar list of factors and market characteristics in practice, which includes such factors as availability of key information concerning market conditions, the extent of firm and product heterogeneity, pricing and marketing practices, characteristics of buyers and sellers and typical transactions as well as previous express collusion. Recently, Sheffman and Coleman (2003) suggested that the value of the "checklist" can be questioned on both theoretical and empirical grounds.

${ }^{8}$ A recent theoretical paper by Compte, Jenny and Rey (2002) also shows that a transaction resulting in a more symmetric distribution of production capacities may increase the risk of collusion. Earlier contributions by Palfrey (1991), Verboven (1997) and Rotschild (1999) show that a change to more similar production costs facilitates collusion in dynamic oligopolies.

${ }^{9}$ The Federal Trade Commission in the US has an extensive history of investigating mergers
} 
market which meets many of the criteria considered conducive to firms' ability to reach and sustain a collusive equilibrium. For instance, the product is homogenous, demand is relatively stable over time and seasonal variation is fairly predictable, variable costs are to a large extent similar for all firms and fluctuations in the variable cost are transparent, the list price is highly transparent, the market has an intermediate concentration level with the Hirschman-Herfindahl index fluctuating in the range of 1500 to 2000 and, finally, the barriers to entry are relatively high as a new entrant would have to establish a comparatively large network of gasoline stations to become a significant competitor in the market.

Despite all these factors conducive to collusive behavior, we find no robust evidence of mergers leading to coordinated effects. Depending on the structural form of the demand function, we find increased concentration to have little impact, no impact or even to increase competition. These results relate in an interesting way to previous studies of collusion in the gasoline retail market. Using micro level data from Vancouver in Canada, Slade (1987 and 1992) finds that prices were strictly higher that prices predicted by a one-shot Nash equilibrium model but, nevertheless, substantially lower that the optimal level for a perfect cartel. In other words, firms were able to sustain some but far from perfect collusion.

The analysis in this paper is also related to Nevo (2001) and a recent paper by Slade (2003). They use structural methods to assess the level of collusion in the US ready-toeat cereal market and the UK brewing industry, respectively. More specifically, they use implied margins from an estimated model with differentiated goods and non-cooperative in petroleum markets. According to its former chairman Robert Pitofsky (2001), the Bureau of Competition at the FTC has spent almost one-third of its total enforcement budget on investigations in energy industries in recent years. Notable, for instance, is the review of the Exxon/Mobil merger in 1999, which resulted in a historically large retail divestiture - the sale of 2,431 Exxon and Mobil gas stations in the Northeast and Mid-Atlantic regions, and in California, Texas and Guam (Exxon Corp., C-3907 (Nov. 30, 1999)). Other recent mergers involving oil companies in the US include BP/Amoco (1999) and Shell/Texaco (1998). In the European Union, on the other hand, the merger task force has reviewed a number of transactions involving gasoline companies. In 1999, the review of the merger between Totalfina and Elf (M. 1628 - Totalfina/Elf Aquitaine (09.02.2000) OJ L143/1 (29 June 2001) pp 682-786), two rival French oil companies, the Commission obtained a divestiture of 70 petrol stations, thereby avoiding that the company would control gasoline retail prices on French highways. 
price competition, to decomposed accounting margins in "collusive" and "non-collusive" components.

The analysis in this paper, on the other hand, focuses on a slightly different problem. The question addressed in this paper is to what extent a merger results in more collusive behavior. Consequently, we are interested in the behavioral change due to mergers rather than the level of collusion as such.

Our results succinctly illustrate that a "checklist" approach to asses collusion and coordinated effects of mergers is problematic. For one thing, the conditions for tacit and express collusion are, in theory, necessary but not sufficient. The empirical relevance of different factors in a specific case is consequently hard to determine (see Dick, 2002). Therefore, we draw the conclusion that the value of a "checklist" in merger control can be questioned on both theoretical and empirical grounds; a conclusion similar to the less formal point made in a recent paper by Sheffman and Coleman, 2003.

The rest of this paper is organized as follows. Section 2 presents facts about the retail market for gasoline and M\&A activity in the Swedish market for gasoline in the 1990's. In addition, market conditions are discussed from the perspective of a simple "checklist". Section 3 starts with the theoretical framework for our analysis and proceeds with the empirical analysis. Finally, section 4 puts our results in a policy context and concludes.

\section{The retail market for gasoline in Sweden}

The Swedish retail market for gasoline is a good candidate for an empirical analysis of coordinated effects of mergers and acquisitions. First and foremost, during the last decades, the market has been subject to significant consolidation. Four major acquisitions and one divestiture occurred during the period 1993-1999. However, except for these transactions, market shares remained fairly stable during the periods between the large transactions. Consequently, it may be argued that any empirical link between variation in market concentration and firm conduct is directly related to the mergers and acquisitions occurring in the industry. Second, and of equal importance, the retail market for gasoline satisfies 
most conditions considered to be necessary for coordinated effects. Moderate concentration, repeated interaction as well as transparency suggest that structural changes could make collusion more likely or efficient.

In addition, the size of the market contributes to the policy relevance of the competitive conditions in this industry. It may be noted that consumption of gasoline at the retail level constitutes a significant share of total private consumption in Sweden. In 2001, the total retail value of gasoline sold at gasoline stations was SEK 51 billion (approximately $\$ 5$ billion), which corresponds to approximately 2.3 percent of GDP or $4.7 \%$ of the private consumption in Sweden. Translated into quantities, the consumption in 2001 was 5418 000 metric tons. ${ }^{10}$ Table A.1 gives some summary statistics of the Swedish retail market for gasoline.

\subsection{Market concentration and M\&A activity}

As previously noted, the retail market for gasoline in Sweden has been subject to significant structural changes, which has resulted in a moderately high concentration. A number of mergers, acquisitions and divestitures has altered the concentration as well as the identities of the main players in the market. Table 1 lists all significant transactions during the period 1985-2002. It is worth noting that the market was less concentrated in the early 1980's, with nine large retail companies, as compared to the late 1990's, when six companies accounted for $96-98 \%$ of the sales.

Figure 1 illustrates the evolution of the Hirschman-Hirfendahl index from 1986 to 2002. During the late 1980's, the HHI was relatively stable, just above 1400. In 1993-1994, the concentration (measured with HHI) increased by almost 240 points when Statoil acquired British Petroleum and another 250 points when OK Petroleum merged with Texaco. In 1995, the concentration decreased after a dissolution of OK Petroleum into OK and Preem.

\footnotetext{
${ }^{10}$ Related to the numbers of cars in traffic, a total of 4018500 cars in 2001, the consumption of gasoline per car in traffic was 1348 liters per annum. This is a lower bound on the mean consumption per car since approximately $5.1 \%$ of the cars in the pool are diesel (automotive gas), which suggests the average consumption per gasoline car to be closer to 1420 liters in 2001.
} 
Table 1: Market structure: significant transactions, 1985-2002.

\begin{tabular}{|c|c|c|c|}
\hline Year & Month & Event & $\begin{array}{l}\text { Market share of } \\
\text { merging (dissolving) firms }\end{array}$ \\
\hline \multirow[t]{3}{*}{1985} & January & Shell acquires Bilisten & NA \\
\hline & & $\begin{array}{l}\text { Norsk Hydro enters through the } \\
\text { acquisition of Mobil. }\end{array}$ & NA \\
\hline & & Statoil enters through the acquisition of Esso & NA \\
\hline 1986 & January & Merger between OK and SP & 0.20 \\
\hline 1991 & January & Statoil and BP station swap & \\
\hline 1993 & October & Statoil acquires BP & 0.26 \\
\hline 1994 & August & Merger between $\mathrm{OK}$ and Texaco & 0.25 \\
\hline 1995 & October & OK and Preem dissolved & $(0.13$ and 0.14$)$ \\
\hline 1996 & May & Norsk Hydro acquires Uno-X & 0.11 \\
\hline 1999 & January & Merger between $\mathrm{OK}$ and $\mathrm{Q} 8$ & 0.26 \\
\hline
\end{tabular}

Later, the concentration increased by 350 points after the merger of OK and Q8 in 1999. It is also worth noting that the $\mathrm{C} 4$ ratio follows a similar pattern. $\mathrm{C} 4$ was approximately $67 \%$ during the period 1986-1992, increased to $75 \%$ in 1994, decreased to $68 \%$ in 1995 , increased by more than ten percentage points to $79 \%$ in 1999 and fell to $75 \%$ in 2000$2001 .^{11}$

${ }^{11}$ In 2001, Statoil of Norway had a market share of 23 percent. It is one of the world's largest net sellers of crude oil and has Scandinavian refineries in Kalundborg, Denmark and Monstad, Norway. Shell had a market share of 13.5 percent. It has Scandinavian refineries in Gothenburg, Sweden and Frederica, Denmark. OK-Q8 with a market share of 26.4 percent is owned by OK and Kuwait Petroleum International, which has a refinery in Europoort, Netherlands. Norsk Hydro had a market share of 11.6 percent. It is a major international oil producer and it has refining capacity at Scanraff in Lysekil, Sweden. Preem, with a market share of 11 percent, has significant refining capacity at two Swedish refineries in Lysekil and Gothenburg. Finally, Jet had a market share of 10.1 percent. It is the trade name for ConocoPhillips gasoline stations in Scandinavia and is a chain of unmanned/automatic gas stations. ConocoPhillips is the sixth largest global oil company and it has European refineries in the UK, Germany and the Czech Republic. 


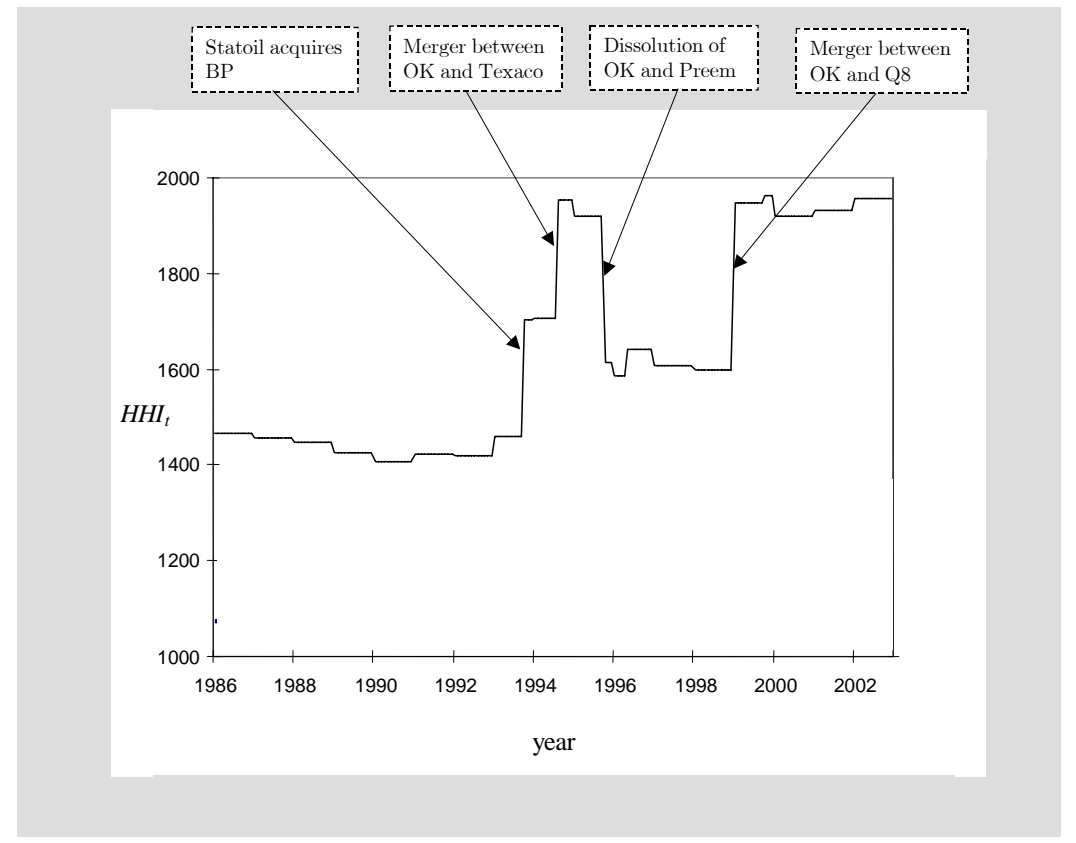

Figure 1: The Herfindahl index 1986-2002.

\subsection{Market conditions}

The traditional approach to coordinated effects in merger cases is to analyze the market characteristics and the conditions for collusion. This section presents several facts about the retail market for gasoline that could be considered conducive to coordinated effects of mergers:

(i) The gasoline market is transparent. Firms set a list price per liter posted at the pump. This price is set on a nationwide basis with minor adjustments to local conditions. Rebates to private customers in loyalty programmes are more or less standardized, and changes are transparent since all firms participate in each other's loyalty programmes. Individual rebates to large customers are less transparent, but also of less significance for the total market.

(ii) The demand for gasoline is stable and predictable. The physical product is homogenous. In the last decade, the consumption of gasoline per month has declined slightly to 
approximately $450000 \mathrm{MT}$ per month. The seasonal pattern is very predictable, with high demand during the summer, low demand in the winter and intermediate demand during the fall and the spring.

(iii) Market demand for gasoline is inelastic. During the period 1995-2000, the real retail price of gasoline increased by 18 percent while consumption declined by $7 \%$, which indicates a price-elasticity of around 0.4 in absolute terms.

(iv) A large share of costs is identical for all firms. In 2001, approximately two thirds of the Swedish retail price could be attributed to specific taxes and the spot market price of premium unleaded gasoline with delivery in North Western Europe. In addition, 20 percent of the retail price was value added tax.

(v) The rate of innovation and technological development is slow. There has been a gradual but slow rationalization at the retail level in the last 20 years. The total number of gas stations of the main retail companies has declined by approximately 500 stations during the period 1987 to 2001.

(vi) Five of the largest retail companies have been prosecuted for an explicit agreement in November 1999 on the terms of a technical rebate adjustment, i.e. a simultaneous reduction of the pump price and rebates (Case T-9902-00 Swedish Competition Authority ./. Norsk Hydro et al).

To summarize, it could be argued that the retail market for gasoline in Sweden has many of the characteristics theoretically considered to be conducive to collusion. In the next section, however, we shall use empirical methods (rather than theoretical criteria) to evaluate the relationship between mergers and collusion. We want to argue that this analysis will indicate the empirical relevance of simple "checklists" in merger control. It will also illustrate the use of econometric techniques in the assessment of collusion in merger cases. 


\section{Empirical analysis}

\subsection{Theoretical framework}

We shall treat gasoline as a homogenous product. Since all firms sell a physically identical product, this is a reasonable approximation despite some differentiation in the distribution of gasoline. Thus, the market demand for gasoline can be written as:

$$
Q_{t}=Q\left(P_{t}, \mathbf{X}_{t}\right)
$$

where $Q_{t}$ is aggregate demand for gasoline in period $t, P_{t}$ is the consumption price for gasoline and $X_{t}$ is a vector of demand shifters such as consumption, the stock of cars etc.

Then, we turn to the behavior of firms. Let $\pi_{i t}$ be the profit of firm $i$ in period $t$, defined as:

$$
\pi_{i t}=\frac{1}{1+\tau} P_{t}\left(Q_{t}\right) q_{i t}-C_{i}\left(q_{i t}, \mathbf{w}_{t}\right),
$$

where $\tau$ is the value added tax, $q_{i t}$ the output of firm $i$ and $C\left(q_{i t}, w_{t}\right)$ is the total cost of the firm, where $w_{t}$ is a vector of input prices and direct taxes. The first-order condition is consequently:

$$
\frac{P_{t}+P_{t}^{\prime}\left(Q_{t}\right) Q_{t} \theta_{i t}}{1+\tau}=\frac{d C_{i}\left(q_{i t}, \mathbf{w}_{t}\right)}{d q_{i t}}
$$

where $P_{t}^{\prime}\left(Q_{t}\right)=\frac{d P_{t}}{d Q_{t}}$ and $\theta_{i t}=\frac{d Q_{t}}{d q_{i t}} \frac{q_{i t}}{Q_{t}}$ is the conjectural variation elasticity. Having only market-level data, we need to rewrite (3). We multiply (3) with the market share of firm $i, s_{i}=\frac{q_{i t}}{Q_{t}}$, and sum over all firms on the market. This yields:

$$
\frac{1}{1+\tau}\left[P_{t}+P_{t}^{\prime}\left(Q_{t}\right) Q_{t} \theta_{t}\right]=c_{t}\left(\mathbf{w}_{t}\right)
$$

where $c_{t}\left(w_{t}\right)=\sum_{i=1}^{N} s_{i} c_{i t}\left(w_{t}\right)$ is a weighted average of marginal costs ${ }^{12}$ and $N$ the number of firms. We shall refer to $\theta_{t}=\sum_{i=1}^{N} s_{i t} \theta_{i t}$ as the (weighted) average industry conduct, which

\footnotetext{
${ }^{12}$ We follow Verboven and Bettendorf (2000) and assume that the cost function can be written as $C_{i t}\left(q_{i t}, \mathbf{w}_{t}\right)=c_{i t}\left(\mathbf{w}_{t}\right) q_{i t}+G_{i}\left(\mathbf{w}_{t}\right)$, where $G_{i}\left(\mathbf{w}_{t}\right)$ are fixed costs.
} 
is our measure of the degree of competition in period $t$. Defining the average Lerner index $L_{t}$ :

$$
L_{t}=\frac{P_{t}-(1+\tau) c\left(\mathbf{w}_{t}\right)}{P_{t}}
$$

and re-arranging (4), we have that

$$
L_{t}=\frac{\theta_{t}}{\epsilon\left(P_{t}\right)},
$$

where $\epsilon\left(P_{t}\right)=-\frac{d Q_{t}}{d P_{t}} \frac{P_{t}}{Q_{t}}$ is the market price elasticity of demand. Given the price elasticity $\epsilon\left(P_{t}\right)$, which can be obtained from (1), average conduct $\theta$ can be estimated as a (possibly time-varying) parameter from (6). The estimates of $\theta$ can then be used to make assessments of the collusive effects of mergers.

Alternatively, we can re-arrange average industry conduct $\theta_{t}$ to obtain:

$$
\theta_{t}=\sum_{i=1}^{N}\left(1+\sum_{j \neq i} \frac{d q_{j t}}{d q_{i t}}\right)\left(\frac{q_{i t}}{Q_{t}}\right)^{2} .
$$

Assuming symmetric conjectures, we can define $R_{t}=\sum_{j \neq i} \frac{d q_{j t}}{d q_{i t}}$ as the total output response by the competitors to an increase in volume by firm $i$ (following Jacquemine and Slade, 1989) and rewrite (7) as:

$$
\theta_{t}=\left(1+R_{t}\right) H H I_{t}
$$

Given a specific functional form of the total output response $R_{t}$, which may depend on the level of concentration as measured by the Hirshman-Herfindahl index $H H I_{t}$, equation (8) can be estimated by replacing industry conduct $\theta_{t}$ with the price-elasticity-adjusted Lerner index, $L_{\epsilon_{t}}$ :

$$
L_{\epsilon_{t}}=\left[1+R_{t}(H H I)\right] H H I_{t}
$$

since $\theta_{t}=L_{\epsilon_{t}}=L_{t} \cdot \epsilon\left(P_{t}\right)$ holds from (6).

Following Jacquemine and Slade (1989), coordinated effects of a merger can now be defined as the increasing effectiveness of, or risk for, "conscious parallel behavior", i.e. $R_{t}^{\prime}\left(H H I_{t}\right)>0$. Defining the elasticity $\eta=\frac{d L_{\epsilon}}{d H H I} \frac{H H I}{L_{\epsilon}}$ (omitting the time index), the hypothesis about coordinated effects of mergers can thus be translated into:

$$
\eta=\frac{d L_{\epsilon}}{d H H I} \frac{H H I}{L_{\epsilon}}=\frac{R^{\prime}(H H I)}{(1+R)}+1>1 .
$$


Consequently, the estimates of $\eta$ can be used to assess the effects of mergers.

\subsection{Demand for gasoline}

Our purpose is to examine how increased concentration induced by mergers affects industry conduct. Generally, the results will crucially depend on the estimated demand elasticities $\varepsilon\left(P_{t}\right)$ from the demand function (1). Therefore, we devote some effort to estimating demand functions. More specifically, we estimate four different specifications: linear, log-linear, exponential and quadratic demand:

$$
\begin{aligned}
Q_{t} & =\alpha_{0}+\alpha_{1} P_{t}+\alpha_{2}^{\prime} \mathbf{X}_{t}+\xi_{t} \\
q_{t} & =\alpha_{0}+\alpha_{1} p_{t}+\alpha_{2}^{\prime} \mathbf{x}_{t}+\xi_{t} \\
Q_{t} & =\alpha_{0}+\alpha_{1} P_{t}^{2}+\alpha_{2}^{\prime} \mathbf{X}_{t}+\xi_{t} \\
Q_{t} & =\exp \left(\alpha_{0}+\alpha_{1} P_{t}+\alpha_{2}^{\prime} \mathbf{X}_{t}+\xi_{t}\right),
\end{aligned}
$$

where $Q_{t}$ is the quantity of gasoline consumed, $P_{t}$ is the price of gasoline, $X_{t}$ are demand shifters and lower case letters denote logs of variables. Control variables include consumption per capita $\left(C O N S_{t}\right)$, the number of private cars in traffic $\left(C A R S_{t}\right)$, and the number of private cars temporarily deregistered $\left(C A R S D_{t}\right)$. We also add a time trend (TREND) and a set of dummy variables $D_{M}$, defined for each month to account for seasonal variation.

The linear demand function (11) allows for varying price elasticities, but has a constant slope-coefficient. The log-linear demand function (12), on the other hand, yields a constant price elasticity. Finally, the last two demand functions, (13)-(14), allow for varying elasticity, as well as a varying slope coefficient.

Table A.2 provides summary statistics. We have monthly data during the period January, 1980 to June, 2002 for the price and quantities sold of gasoline, oil price, and the number of private cars in traffic and the number of temporarily deregistered cars. The two latter series are translated into an index, using 1985 January as the base period. Quarterly data is used on current household per capita consumption. Finally, the gasoline prices and 
oil prices are in Swedish kronor per liter. Gasoline input price data, as measured by the Rotterdam FOB spot market price of premium unleaded gasoline, is available from June, 1985.

Table 2 shows the result of estimating demand specifications (i)-(iv). All regressions make use of instrumental variables for the gasoline price, i.e. a two-stage least squares method is employed, since a contemporaneous correlation between error term and gasoline prices may be suspected. Different types of shocks, which affect the error term $\xi$, can also affect the gasoline prices, since these are sensitive to world-wide shocks such as political crises, wars etc. We instrument the price of gasoline with the oil price and direct taxes, which are highly correlated with prices. Using the oil price rather than the input price for gasoline allows us to make use of the full sample period in estimating the demand functions, since gasoline input prices are only available from $1985 .{ }^{13}$

All specifications are estimated with high precision. The fit is generally high, and most coefficients are highly significant with the expected signs. In particular, we find the price of gasoline to be significantly negatively related to demand, while disposable income (proxied for by consumption per capita), CONS and the stock of cars, CARS, increases the demand for gasoline. As expected, the different specifications generate some variation in the estimated price elasticities of demand.

To test for parameter stability, we tested for recursive least square coefficients, which detected no shift in the estimated parameters. We also applied a Chow test to examine whether there is a structural shift in the estimated parameters in the demand functions before and after the introduction of VAT in March 1990. All demand functions show signs of a change in the estimated parameters before and after March 1990, a problem further discussed below.

\footnotetext{
${ }^{13}$ While this improves our estimates because the standard errors are smaller, using the shorter period with the input prices yields qualitatively the same results.
} 
Table 2: Estimation of demand.

\begin{tabular}{|c|c|c|c|c|}
\hline Specification & (i) & (ii) & (iiii) & (v) \\
\hline Demand: & Linear & Logaritmic & Quadratic & Expon. \\
\hline PRICE & $\begin{array}{l}-0.067^{* * *} \\
(-7.30)\end{array}$ & $\begin{array}{l}-0.238^{* * *} \\
(-5.36)\end{array}$ & $\begin{array}{l}-0.005^{* * *} \\
(-8.77)\end{array}$ & $\begin{array}{l}-0.056^{* * *} \\
(-7.31)\end{array}$ \\
\hline$G D P C$ & $\begin{array}{l}0.227^{* * *} \\
(4.48)\end{array}$ & $\begin{array}{l}0.486^{* * *} \\
(9.24)\end{array}$ & $\begin{array}{l}0.191^{* * *} \\
(3.56)\end{array}$ & $\begin{array}{l}0.195^{* * * *} \\
(4.58)\end{array}$ \\
\hline$C A R S$ & $\begin{array}{l}1.032^{* * *} \\
(3.97)\end{array}$ & $\begin{array}{l}0.571^{* * *} \\
(5.36)\end{array}$ & $\begin{array}{l}0.925^{* * *} \\
(3.72)\end{array}$ & $\begin{array}{l}0.807^{* *} \\
(-3.72)\end{array}$ \\
\hline$C A R S D$ & $\begin{array}{l}-0.218^{* * *} \\
(-4.63)\end{array}$ & $\begin{array}{l}-0.161^{* * *} \\
(-4.69)\end{array}$ & $\begin{array}{l}-0.171^{* * *} \\
(-3.69)\end{array}$ & $\begin{array}{l}-0.172^{* * *} \\
(-4.37)\end{array}$ \\
\hline TREND & $\begin{array}{l}-0.024^{* * *} \\
(-4.14)\end{array}$ & $\begin{array}{l}-0.016^{* * *} \\
(-5.77)\end{array}$ & $\begin{array}{l}-0.014^{* *} \\
(-2.38)\end{array}$ & $\begin{array}{l}-0.019^{* * *} \\
(-4.03)\end{array}$ \\
\hline CONST & $\begin{array}{l}46.689^{* * *} \\
(4.16)\end{array}$ & $\begin{array}{l}56.329^{* * *} \\
(5.99)\end{array}$ & $\begin{array}{l}28.561^{* *} \\
(2.39)\end{array}$ & $\begin{array}{l}37.086 \\
(3.97)\end{array}$ \\
\hline$R 2$ & 84.11 & 87.04 & 85.04 & 83.71 \\
\hline$F$ & $106.48^{* * *}$ & $125.65^{* * *}$ & $124.41^{* * *}$ & $87.88^{* * *}$ \\
\hline Obs & 275 & 275 & 275 & 275 \\
\hline
\end{tabular}

${ }^{1}$ Note: ${ }^{*},{ }^{* *}, * * *$ indicate the significance at the ten percent, five percent and one percent level, respectively.

\subsection{Investigating the Lerner index}

We are now ready to proceed with the analysis of the relationship between mergers and collusion. Thus, we begin by examining the evolution of the Lerner index, $L_{t}$. For this purpose, let the marginal cost $c\left(\mathbf{w}_{t}\right)$ in (5) be:

$$
c\left(\mathbf{w}_{t}\right)=c_{0}+T A X_{t}+P S P O T_{t},
$$

where $T A X_{t}$ is direct taxes on gasoline in sek/liter, $P S P O T_{t}$ is the Rotterdam spot market price $^{14}$ in sek/liter and $c_{0}$ contains several unobserved components of marginal cost (e.g. labor and transportation cost), for which we have no data. We shall measure marginal

\footnotetext{
${ }^{14}$ This input price is multiplied by 0.755 , which is a conversion factor.
} 
cost directly as the sum of direct taxes $T A X_{t}$ plus the spot price of unleaded premium gasoline, i.e. $c\left(w_{t}\right)=T A X_{t}+P S P O T_{t}$. As noted above, these components (including VAT) account for 88 percent of the retail price of gasoline on average but nevertheless, this is a lower bound as we shall initially assume $c_{0}=0$.

Equation (6) represents a theoretical relationship between the Lerner index $L_{t}$ and price elasticity $\epsilon\left(P_{t}\right)$, where $\theta$ indicates the degree of competition. To investigate this relationship, we calculate $L_{t}$ by inserting (15) into (5) and the price elasticity $\epsilon\left(P_{t}\right)=-\frac{d Q}{d P} \frac{P}{Q}$ from the demand equations (11)-(14). Figure 2 illustrates this relationship for the the linear, quadratic- and exponential demand functions. Upon inspection, the data seems to roughly cluster into three separate periods.

First, note that within the pre-VAT benchmark period, i.e. observations occurring before the introduction of VAT in March 1990 (indicated with 0:s in Figure 2), the Lerner index and price elasticity seem virtually unrelated, which may indicate perfect competition, or the use of some other price setting behavior than (4). In contrast, for observations occurring during the merger period, i.e. observations occurring after the merger between Statoil and BP in 1993 (indicated with M:s in Figure 2), there seems to be a clear negative relationship between the Lerner index and price elasticity, suggesting an imperfectly competitive market. Finally, within the post-VAT benchmark period, i.e. observations occurring after the introduction of VAT in 1990, but before the Statoil and BP merger in 1993 (indicated with 1:s in Figure 2), there does not seem to be any clear-cut relationship. However, at least for the quadratic and the exponential demand specifications, aggregating observations in the post-VAT benchmark and merger periods, there seems to be a rather similar overall pattern.

To more formally investigate these patterns, we turn to estimations. Note that (6) represents a non-linear relationship between $L_{t}$ and $\epsilon\left(P_{t}\right)$. However, by rewriting this expression using the inverse price elasticity $\rho\left(Q_{t}\right)=\frac{1}{\epsilon\left(P_{t}\right)}$, adding a constant term and an 


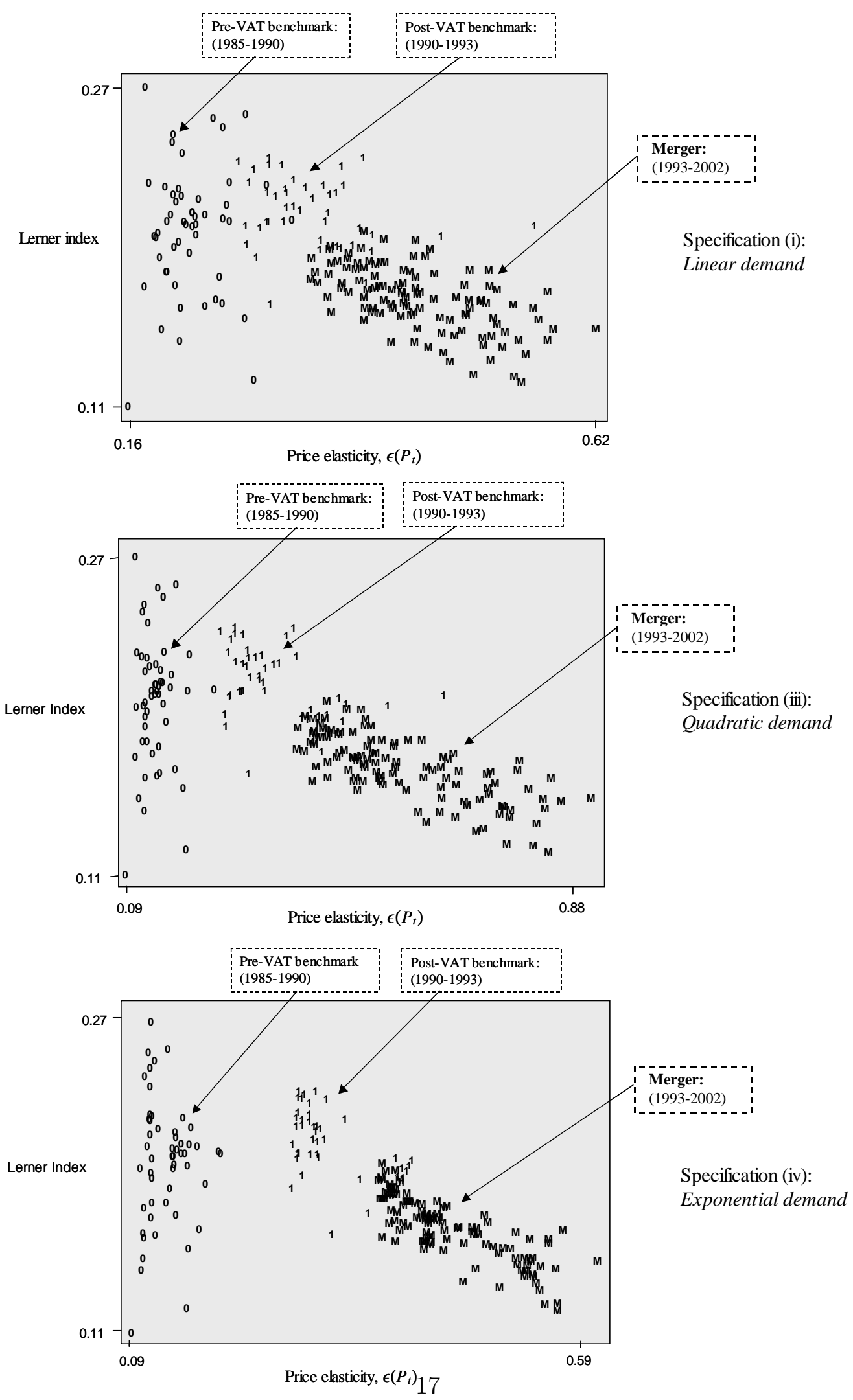

Figure 2: The Lerner index and Price Elasticity. 
error term, we have a simple linear regression to estimate ${ }^{15}$

$$
L_{t}=\beta_{0}+\theta \rho\left(Q_{t}\right)+\varepsilon_{t},
$$

where we also include monthly dummies to control for seasonal effects and apply robust standard errors since $\rho\left(Q_{t}\right)$ is estimated.

We estimate (16) separately for all three periods and all demand specifications. The results are given in Table 3 and roughly confirm the visual image of the evolution of conduct in Figure 2. In the pre-VAT benchmark period, we cannot reject $\theta=0$ for any specification. For the linear specification, the estimated conduct in the post-VAT benchmark period is 0.027, whereas for the quadratic and exponential specifications, the estimated conduct is 0.017 and 0.04 , respectively. All these estimates are significantly different from zero, but the fit of these regressions is generally quite low and F-tests reject the joint significance of parameters. Examining the estimates for conduct during the merger period, we can note that this period produces the highest conduct, irrespective of specification, ranging from 0.035-0.069. While these estimates suggest conduct to be rising over time and that this process may be related to the increase in concentration occurring between periods, there are several caveats.

One caveat is the structural break in demand upon the introduction of VAT in March 1990. We examined its impact by re-estimating the demand equations (11)-(14) before and after the introduction of VAT. This leads to a smaller estimate of the slope-coefficient $\alpha_{1}$ in the post-VAT period, implying a less elastic demand at that time. However, the relationship between $L_{t}$ and $\epsilon\left(P_{t}\right)$ is not qualitatively affected, since $\epsilon\left(P_{t}\right)$ (or its inverse $\left.\epsilon\left(Q_{t}\right)\right)$ is simply re-scaled. ${ }^{16}$

\footnotetext{
${ }^{15}$ We also estimated this regression using instrumental variables to control for the endogeneity bias as the price elasticity might be endogenous. Instrumenting with lags of the price elasticity did not qualitatively change the results, however.

${ }^{16}$ For instance, the price elasticity of linear demand is $\epsilon\left(P_{t}\right)=-\frac{d Q}{d P} \frac{P}{Q}=-\alpha_{1 z} \frac{P}{Q}$, where $z$ indicates the pre- or post-VAT period. Increasing $\alpha_{1}$ for the pre-VAT observations then simply pushes those observations to the right in Figure 2, while reducing $\alpha_{1}$ for the post-VAT observations shifts such observations to the left.
} 
Another concern is the estimate of the constant term, $\beta_{0}$. Note that by comparing (6) and (16), theory would suggest that $\hat{\beta}_{0}=0$. In contrast, in Table 3, we observe that while $\hat{\beta}_{0}$ is decreasing over time, it is estimated significantly differently from zero in all specifications. ${ }^{17}$ To some extent, this may be explained by the omission of the unobserved cost component $c_{0}$ in (15). From (5), (15) and (16), it follows that $\beta_{0}=\frac{(1+\tau) c_{0}}{P_{t}}$; that is, the estimate of the constant term $\hat{\beta}_{0}$ picks up the average (relative) measurement error arising from omitting $c_{0}$ in (5). Solving for $c_{0}$ and taking the average for the respective time periods, we find the unobserved marginal cost component to be roughly SEK 0.80 in the pre-VAT and post-VAT benchmark periods, while this component is SEK 0.47 in the merger period. As discussed in the robustness section 3.5 below, we estimate that the unobserved component is approximately 0.4 SEK, which is also consistent with rough estimates available from industry sources. This suggests that $\beta_{0}$ may be over-estimated in (16) during the pre-merger periods, which may bias the estimate of industry conduct downwards. One reason is that since $\beta_{0}=\frac{(1+\tau) c_{0}}{P_{t}}$, estimates of $\beta_{0}$ may decrease over time if gasoline prices $P_{t}$ increase faster than the unobserved component $c_{0}$. As illustrated in Figure 3, this may also have been the case since gasoline prices increase substantially due to increased direct taxation and higher spot market prices, in particular in the later part of the merger period. In addition, with greater variation in prices and demand elasticities, the relationship in (16) is also better identified, as suggested by the superior overall fit and the joint significance of parameters shown in Table 3 for the merger period.

In brief, our results so far suggest that conduct is rising over time which could be related to consolidation. We are nevertheless careful not to draw any definite conclusions based on this finding due to a structural break in demand and due to the potential influence of several unobserved components of marginal cost.

To further investigate whether increased concentration has resulted in less competitive

\footnotetext{
${ }^{17}$ We also estimated a piece-wise linear regression of (16), which allows for different intercepts and slopes during the three periods. Applying Wald tests, we could then confirm that the average conduct in the Merger period exceeds the level of conduct in the Benchmark period and that the Lerner index is reduced over time.
} 
industry conduct, we now proceed to estimating conduct as a direct function of market concentration (HHI). For this purpose, we turn to examining the elasticity adjusted Lerner index.

Table 3: The relationship between the Lerner index and price elasticity.

\begin{tabular}{|c|c|c|c|c|}
\hline Specification & (i) & (ii) & (iiii) & (iv) \\
\hline Demand: & Linear & Logaritmic & Quadratic & Expon. \\
\hline \multicolumn{5}{|c|}{ Pre-VAT benchmark period: November 1985 - February 1990} \\
\hline$\hat{\theta}$ & $\begin{array}{c}-0.002 \\
(-0.14)\end{array}$ & . & $\begin{array}{c}-0.001 \\
(-0.18)\end{array}$ & $\begin{array}{c}0.002 \\
(0.09)\end{array}$ \\
\hline Constant & $\begin{array}{l}0.190^{\text {*** }} \\
(2.40)\end{array}$ & $\begin{array}{l}0.200^{\text {*** }} \\
(11.52)\end{array}$ & $\begin{array}{l}0.187^{\text {*** }} \\
(3.78)\end{array}$ & $\begin{array}{l}0.193^{* *} \\
(2.50)\end{array}$ \\
\hline $\mathrm{R} 2$ & 0.15 & 0.15 & 0.15 & 0.15 \\
\hline $\mathrm{F}$ & 0.59 & 0.66 & 0.59 & 0.59 \\
\hline Obs & 52 & 52 & 52 & 52 \\
\hline \multicolumn{5}{|c|}{ Post-VAT benchmark period: March 1990 - September 1993} \\
\hline$\hat{\theta}$ & $\begin{array}{l}0.027^{* * *} \\
(-3.36)\end{array}$ & . & $\begin{array}{l}0.017^{* * *} \\
(-3.52)\end{array}$ & $\begin{array}{l}0.040^{* * * *} \\
(3.48)\end{array}$ \\
\hline Constant & $\begin{array}{l}0.150^{\text {*** }} \\
(6.76)\end{array}$ & $\begin{array}{r}0.211 \\
(19.62)\end{array}$ & $\begin{array}{l}0.168^{* * *} \\
(9.19)\end{array}$ & $\begin{array}{l}0.104^{\text {*** }} \\
(3.24)\end{array}$ \\
\hline $\mathrm{R} 2$ & 0.40 & 0.18 & 0.42 & 0.18 \\
\hline $\mathrm{F}$ & 1.68 & 0.60 & 1.79 & 1.76 \\
\hline Obs & 43 & 43 & 43 & 43 \\
\hline \multicolumn{5}{|c|}{ Merger period: October 1993 - November 2002} \\
\hline$\hat{\theta}$ & $\begin{array}{l}0.047^{* * *} \\
(12.26)\end{array}$ & . & $\begin{array}{l}0.035^{\text {*** }} \\
(13.54)\end{array}$ & $\begin{array}{l}0.069^{* * *} \\
14.98\end{array}$ \\
\hline Constant & $\begin{array}{l}0.072^{\text {*** }} \\
(8.44)\end{array}$ & $\begin{array}{r}0.170 \\
(29.91)\end{array}$ & $\begin{array}{c}0.092^{* * *} \\
(14.75)\end{array}$ & $\begin{array}{l}0.020^{* *} \\
(2.02)\end{array}$ \\
\hline$R 2$ & 0.63 & 0.06 & 0.67 & 0.67 \\
\hline $\mathrm{F}$ & $13.73^{* * *}$ & 0.52 & 16.64 & 19.96 \\
\hline Obs & 110 & 110 & 110 & 110 \\
\hline
\end{tabular}

${ }^{1}$ Note: $*{ }^{* *},{ }^{* * *}$ indicate the significance at the ten percent, five percent and one percent level, respectively. 


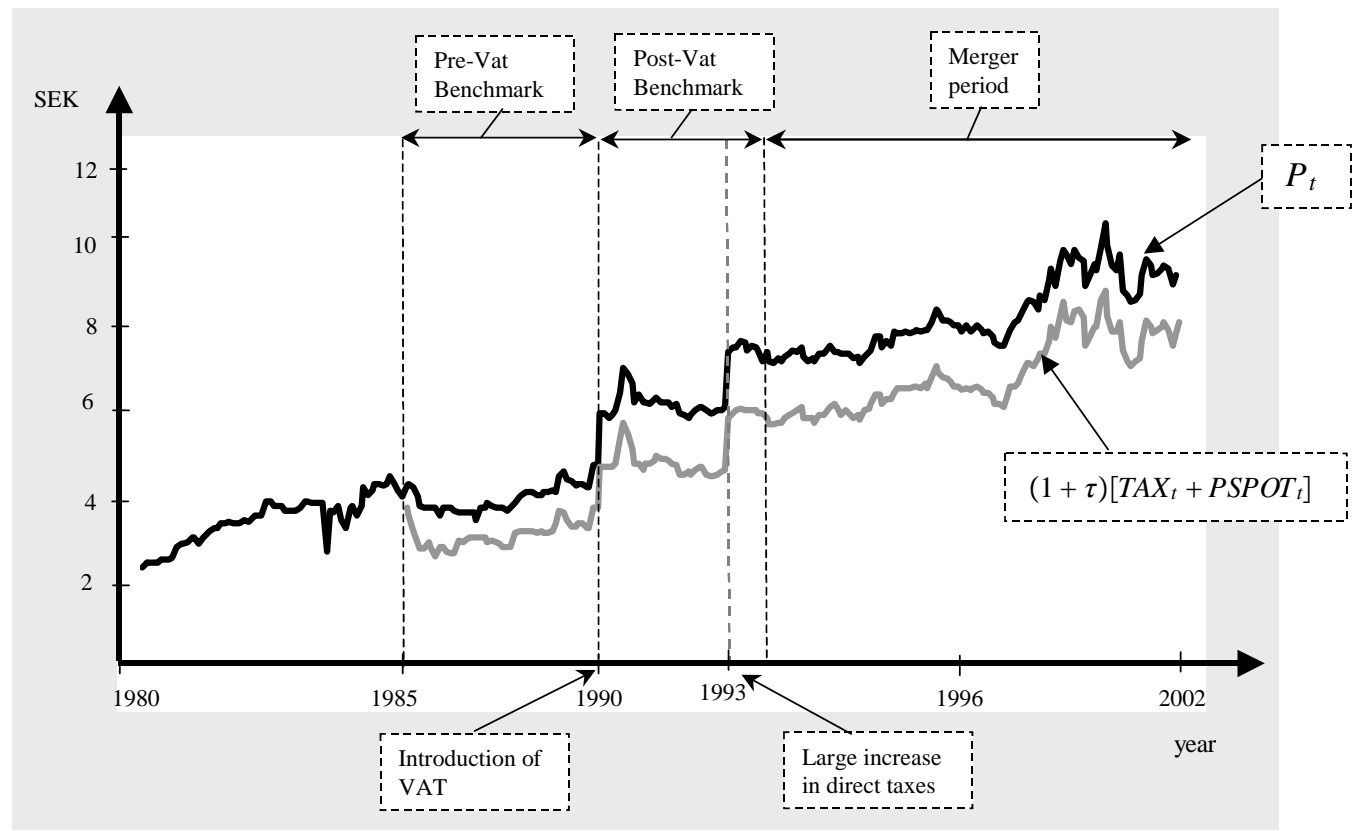

Figure 3: The evolution of the price of gasoline and the measure of marginal cost in (5).

\subsection{Investigating the elasticity adjusted Lerner index}

The structural presumption in merger control implies that an increase in concentration should result in less competition and an increased risk of collusion. In other words, there should be a positive relationship between conduct and HHI. In section 3.1, we showed that industry conduct $\theta$ could be directly measured by the elasticity adjusted Lerner index, $L_{\epsilon_{t}}$, and that a direct relation between conduct and concentration could also be derived. For our empirical purposes, we assume there to exist a non-linear relationship between the competitors' output response and HHI, which takes the parametric functional form $R_{t}=\alpha H H I_{t}^{\eta-1}-1$. Our measure of conduct in (9) can thus be written as:

$$
L_{\epsilon_{t}}=\alpha H H I_{t}^{\eta} \text {, }
$$


where $\alpha, \eta \geq 0 .{ }^{18}$ Taking logs, we then obtain the following equation to be estimated:

$$
\ln L_{\epsilon_{t}}=\ln \alpha+\eta \ln H H I_{t}+\varepsilon_{t},
$$

where $\varepsilon_{t}$ is an error term. We include monthly dummies to control for seasonal variation and since the dependent variable is estimated, robust standard errors are applied. Note that from (10), coordinated effects should imply that the elasticity of conduct with regard to HHI should exceed unity, $\eta>1$, whereas non-cooperative Cournot implies $\alpha=\eta=1$.

In estimating (18), we need to control for the structural shift in demand found upon the introduction of VAT; this will otherwise bias our estimate of $\eta$ in (18). A shock will directly affect the dependent variable $L_{\epsilon_{t}}=L_{t} * \epsilon\left(P_{t}\right)$, by affecting $\epsilon\left(P_{t}\right)$. To control for this problem and isolate the influence on conduct from concentration, we only estimate (18) on observations after VAT was introduced, i.e. we use data from March 1990-November 2002. This implies that we have roughly three years of data from the Post-VAT benchmark period and roughly ten years of data from the merger period. We also re-estimate (18) assuming clustered standard errors, since we have derived the Herfindahl-Hirshman index by roughly combining yearly data on the market shares of market firms with information on the date of the major transactions in Table 1 (clustered t-statistics are given below the non-clustered t-statistics in square-brackets). ${ }^{19}$ Finally, we examine (18), making a different assumption of the unobserved component $c_{0}$ in (15). Initially, we make the simple assumption of $c_{0}=0$ and then check whether the results change when making alternative assumption of $c_{0}$.

The results from estimating (18) are shown in Table 4, where a number of features can be noted. The relationship between conduct and HHI crucially depends on the assumed functional form of demand. Only the linear and quadratic demand functions reveal a positive and significant relationship. The logaritmic demand specification shows conduct to decrease in concentration, but this simply reflects the fact that the Lerner index decreases

\footnotetext{
${ }^{18}$ This gives a slightly more general relationship than that of Willig (1991), where the relationship is linear in HHI, i.e. $\theta=a H H I$.

${ }^{19}$ Moulton (1999) shows that not adjusting for clustering may under-estimate the standard errors for estimated coefficients.
} 


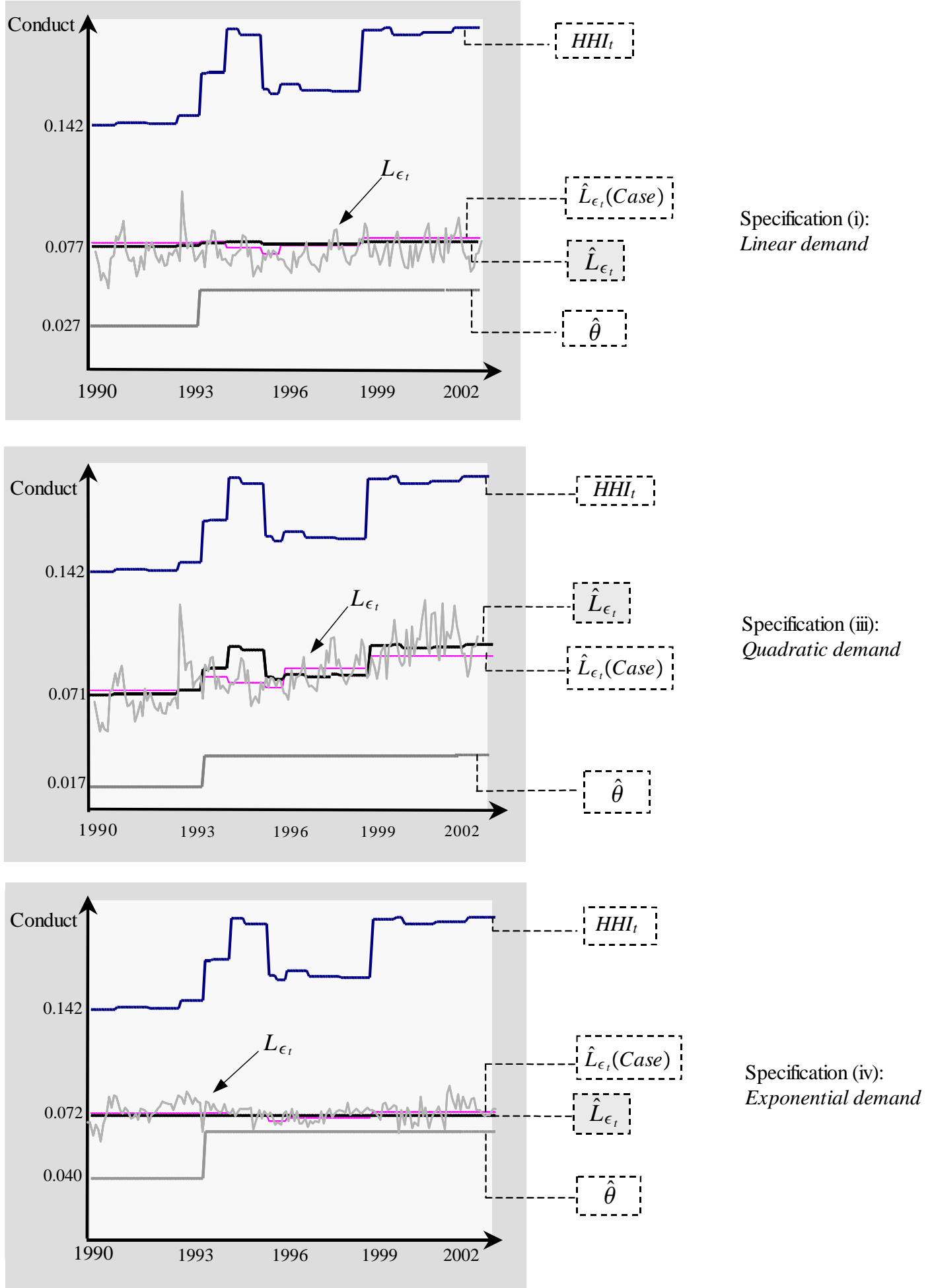

Figure 4: Comparing predicted conduct and concentration. 
over time, since price elasticity does not vary with the log-linear demand function. As concerns the exponential demand function, for which there is variation in price elasticity, no evidence of a correlation between conduct and concentration is found.

For the demand specifications with a positive relationship, we find weak effects. While significantly different from zero, the linear demand produces an estimate of $\hat{\eta}=0.121$ from which we can reject a unity restriction using a Wald test. When re-estimating the relationship, allowing for clustered standard errors, this estimate even turns out to be insignificant as clustering considerably increases standard errors. The quadratic specification produces an estimate $\hat{\eta}=0.975$, which is significant both with and without clustering. Here, we cannot reject the restriction $\eta=1$, which suggests that changes in concentration lead to changes in conduct in a way predicted by Cournot behavior. Hence, at most, we find unilateral effects of mergers, while we can reject coordinated effects.

Next, we examine the levels of predicted conduct. All specifications but quadratic demand have negative constant terms. For instance, for the linear demand specification, the point estimate for $\ln \alpha$ is -2.392 , which is significantly different from the parameter value implied by Cournot behavior (i.e. $\ln \alpha=0$ ). This suggests the estimated level of conduct $\hat{L}_{\epsilon_{t}}$ to be low. This is also in illustrated in Figure 4, where we plot predicted conduct $\hat{L}_{\epsilon_{t}}$ from the linear, quadratic- and exponential demand functions. For comparison, we also plot the actual values of our measure direct of conduct $L_{\epsilon_{t}}$, the Hirschman-Herfindahl index $\mathrm{HHI}_{t}$ (which should equal conduct under pure Cournot competition) as well as our direct estimate of conduct from the Lerner index in (16), $\hat{\theta}$. Added are also predictions of a case-by-case estimation of $L_{\epsilon_{t}}$, labeled $\hat{L}_{\epsilon_{t}}($ case), which is discussed below.

All specifications generate substantially lower predicted values of conduct than expected from non-cooperative Cournot behavior, i.e. $\hat{L}_{\epsilon_{t}}<H H I_{t}$. The co-movement of $\hat{L}_{\epsilon_{t}}$ and $H H I_{t}$ mirrors the estimates of elasticity $\eta$ in Table 4 , where only the quadratic specification is sensitive to changes in concentration. The weak relation between conduct and concentration is also directly evident from comparing the direct measure of conduct, $L_{\epsilon_{t}}$ and $H H I_{t}$.

An interesting observation is that while our direct estimate of conduct $\hat{\theta}$ from (16) 
is smaller than the indirect estimate $\hat{L}_{\epsilon_{t}}$ from (18), only the former reveals a significant increase in conduct for the merger period beginning in 1993. Section 3.3 suggested that the increase in $\hat{\theta}$ may be explained by the unobserved component, $c_{0}$, in (15). In Table 5 , we investigate how different assumptions for $c_{0}$ affect the elasticity adjusted $L_{\epsilon_{t}}$ and the estimates in (16) using the linear demand function. For comparison, specification (i) restates the results $c_{0}=0$. In specification (ii), we increase $c_{0}=0.40 \mathrm{SEK}$, which was argued to be a reasonable estimate in section 3.3. Comparing specifications (i) and (ii), estimates of elasticity $\eta$ are almost identical. However, the estimates of $\ln \alpha$ are now smaller and the level of estimated conduct $\hat{L}_{\epsilon_{t}}$ within the merger period is now very similar to the direct estimates $\hat{\theta}$ from (16), with an average of 0.05 . In section 3.3, we showed that the increase in estimated conduct from $\hat{\theta}=0.027$ in the Post-VAT benchmark period to $\hat{\theta}=0.047$ in the merger period also implied that $c_{0}$ would be around 0.80 SEK in the former and 0.40 in the latter period. Using these numbers in specification (iii), we find a strong increase in elasticity to $\hat{\eta}=2.65$, thereby indicating coordinated effects. Predicting the implied conduct $\hat{L}_{\epsilon_{t}}$, we find that the average conduct during the benchmark period is now 0.028 , and the corresponding predicted average conduct during the merger period is 0.049 , which simply retrieves the above direct estimates, $\hat{\theta}$. However, restricting the sample to the merger period in specification (iv) leads to a sharp reduction to $\hat{\eta}=0.308$, which indicates weak effects of higher concentration.

In all, this shows that the increase in estimated conduct found in section 3.3 , is likely to be driven by attributing a too high marginal cost to the benchmark period, and not by an increase in concentration in the merger period.

It may also be the case that other unobserved factors associated with mergers affect conduct and increase the risk of collusion. Therefore, we finally examine the post-merger effects on a case-by-case basis, measuring the incremental contribution to conduct from each merger and acquisition. Once more, we use the elasticity adjusted Lerner index as our measure of conduct, retaining the assumption of $c_{0}=0$. We estimate the following 
Table 4: Examining conduct and concentration.

\begin{tabular}{|c|c|c|c|c|c|c|}
\hline \multirow{2}{*}{$\begin{array}{l}\text { Spec. } \\
\text { Dem. }\end{array}$} & \multirow{2}{*}{$\frac{(i)}{\text { Linear }}$} & \multirow{2}{*}{$\frac{\text { (ii) }}{\text { Logaritmic }}$} & \multirow{2}{*}{$\frac{\text { (iii) }}{\text { Quadratic }}$} & \multirow{2}{*}{$\frac{\text { (iv) }}{\text { Exponential }}$} & \multicolumn{2}{|c|}{ Restrictions: } \\
\hline & & & & & $\begin{array}{l}\text { Non-coop. } \\
\text { Cournot }\end{array}$ & $\begin{array}{l}\text { Coordin. } \\
\text { effects }\end{array}$ \\
\hline$\eta$ & $\begin{array}{l}0.121^{* *} \\
(2.06) \\
{[1.27]}\end{array}$ & $\begin{array}{c}-0.839 * * * \\
(-12.21) \\
{[-4.56]}\end{array}$ & $\begin{array}{c}0.975^{* * *} \\
(10.12) \\
{[4.10]}\end{array}$ & $\begin{array}{l}0.016 \\
(0.32) \\
{[0.17]}\end{array}$ & 1 & $>1$ \\
\hline $\ln \alpha$ & $\begin{array}{l}-2.392^{* * *} \\
(-22.76) \\
{[-13.53]}\end{array}$ & $\begin{array}{l}-4.643^{* * *} \\
(-36.53) \\
{[-14.11]} \\
\end{array}$ & $\begin{array}{l}-0.727^{* * *} \\
(-4.14) \\
{[-1.68]}\end{array}$ & $\begin{array}{l}-2.528^{* * *} \\
(-28.80) \\
{[-15.01]}\end{array}$ & 0 & no restrict. \\
\hline $\mathrm{R} 2$ & 0.58 & 0.54 & 0.57 & 0.06 & & \\
\hline $\mathrm{F}$ & $14.28^{* * *}$ & $8.38^{* * *}$ & $15.92^{* * *}$ & 1.88 & & \\
\hline Obs. & 153 & 153 & 153 & 153 & & \\
\hline
\end{tabular}

Note: $*, * *, * * *$ indicate the significance at the one percent, five percent and ten percent level, respectively. Values below estimate parentheses indicate t-values. Values below estimate brackets indicate clustered t- values. Seasonal dummies are included in all specifications.

equation:

$$
\begin{aligned}
L_{\epsilon_{t}} & =\beta_{0}+\beta_{1} D_{\text {Statoil }+B P}+\beta_{2} D_{O K+\text { Texaco }}+\beta_{3} D_{O K-\text { Preem }} \\
& +\beta_{4} D_{\text {Hydro }+ \text { UnoX }}+\beta_{5} D_{O K+Q 8}+\xi_{t} .
\end{aligned}
$$

$\beta_{0}$ measures the average conduct during the pre-VAT benchmark period. $D_{\text {Statoil }+B P}$ is then a dummy variable taking the value of one from October 1993, and zero prior to this month. It measures the average effect on conduct, due to the change in market structure as a result of the Statoil/BP merger. $D_{O K+\text { Texaco }}, D_{O K-P r e e m}, D_{H y d r o+U n o X}$ and $D_{O K+Q 8}$ are similarly defined. Finally, dummy variables $D_{M}$ defined for each month control for seasonal variation.

The results from estimating (19) are given in Table 6. These case-by-case estimates, labeled $\hat{L}_{\epsilon_{t}}$ (case) in Figure 4, generate very similar results as the functional relationship presented in Table 4. The level of estimated conduct is once more very stable and only the quadratic demand function reveals any effects. Table 6 also shows the source of this stability of conduct as it also contains estimates of (19) when replacing the dependent variable with the Lerner index $L_{t}$ and price elasticity $\varepsilon\left(P_{t}\right)$. Irrespective of specification, 
Table 5: Sensitivity of assumptions about the marginal cost using linear demand.

\begin{tabular}{|c|c|c|c|c|c|c|}
\hline \multirow{2}{*}{$\begin{array}{l}\text { Spec. } \\
\text { Assump. }\end{array}$} & (i) & (ii) & (iii) & (iv) & \multicolumn{2}{|c|}{ Restrictions: } \\
\hline & $\mathrm{c}_{0}=0$ & $\mathrm{c}_{0}=0.4$ & $\begin{array}{l}c_{0}^{\text {Benchmark }}=0.8 \\
c_{0}^{\text {Merger }}=0.4\end{array}$ & $\begin{array}{l}\mathrm{c}_{0}=0.4 \\
\text { Only Merger } \\
\text { period used }\end{array}$ & $\begin{array}{l}\text { Non-coop. } \\
\text { Cournot }\end{array}$ & $\begin{array}{l}\text { Coordin. } \\
\text { effects }\end{array}$ \\
\hline$\eta$ & $\begin{array}{l}0.121^{* *} \\
(2.06) \\
{[1.27]}\end{array}$ & $\begin{array}{l}0.125 \\
(1.47) \\
{[0.87]}\end{array}$ & $\begin{array}{c}2.659^{* * *} \\
(12.59) \\
{[5.40]}\end{array}$ & $\begin{array}{l}0.308^{* * *} \\
(2.69) \\
{[1.43]}\end{array}$ & 1 & $>1$ \\
\hline $\ln \alpha$ & $\begin{array}{l}-2.392^{* * *} \\
(-22.76) \\
{[-13.53]}\end{array}$ & $\begin{array}{l}-2.834^{* * *} \\
(-18.54) \\
{[-14.11]}\end{array}$ & $\begin{array}{l}1.504^{* * *} \\
(3.94) \\
{[1.74]}\end{array}$ & $\begin{array}{l}-2.520^{* * *} \\
(-12.68) \\
{[-15.01]}\end{array}$ & 0 & no restrict. \\
\hline $\mathrm{R} 2$ & 57.8 & 42.0 & 60.7 & 45.1 & & \\
\hline $\mathrm{F}$ & $14.28^{* * *}$ & $7.77^{* * *}$ & $18.02^{* * *}$ & $9.87 * * *$ & & \\
\hline Obs. & 153 & 153 & 153 & 110 & & \\
\hline
\end{tabular}

Note: *,**,** indicate the significance at the one percent, five percent and ten percent level, respectively. Values below estimate parentheses indicate t- values. Values below estimate brackets indicate clustered t- values. Seasonal dummies are included in all specifications.

the Lerner index $L_{t}$ and price elasticity $\varepsilon\left(P_{t}\right)$ tend to move in separate directions, offsetting or reducing changes in our measure of conduct, $L_{\epsilon_{t}}=L_{t} \cdot \varepsilon\left(P_{t}\right)$. The only merger for which we do find consistent significant effects is that between OK and Q8. However, as can be seen from Table 6 , the effects are very modest.

In all, this shows very small effects of mergers, which is the case irrespective of measuring the effect of increased concentration, or using a case-by-case approach. There is no clear evidence of coordinated effects.

The fact that effects of mergers on conduct are modest could be due to numerous factors. The anti-competitive effects could be mitigated by potential competition, efficiencies or, alternatively, the presence of a maverick. It clearly highlights the importance of analyzing all the relevant factors for competition in the assessment of post-merger effects. The measurement of post-merger effects on a case-by-case basis reconfirms that a substantial increase in concentration may or may not result in less competition (i.e. a higher level of conduct). This reinforces the conclusion in the previous section that the change in HHI is a poor predictor of post-merger conduct, at least at the present level of concentration. 
Table 6: Lerner-index, price elasticity and conduct.

\begin{tabular}{|c|c|c|c|c|c|c|c|c|}
\hline \multirow{2}{*}{$\begin{array}{l}\text { Demand: } \\
\text { Specification: }\end{array}$} & \multirow{2}{*}{ Lerner } & \multicolumn{2}{|c|}{ Linear } & \multicolumn{2}{|c|}{ Quadratic } & \multicolumn{2}{|c|}{ Exponential } & \multirow{2}{*}{$\begin{array}{c}\text { Log-linear } \\
\text { (ii) } \\
\text { Conduct } \\
\end{array}$} \\
\hline & & (i) & (ii) & (i) & (ii) & (i) & (ii) & \\
\hline $\begin{array}{l}\text { Benchmark } \\
\text { (March 1990) }\end{array}$ & $\begin{array}{l}0.216^{* * *} \\
(70.96)\end{array}$ & $\begin{array}{l}0.340^{* * *} \\
(37.23)\end{array}$ & $\begin{array}{l}0.074^{* * *} \\
(46.93)\end{array}$ & $\begin{array}{l}0.335^{* * *} \\
(24.70)\end{array}$ & $\begin{array}{l}0.073^{* * *} \\
(32.89)\end{array}$ & $\begin{array}{l}0.363^{* * *} \\
(70.79)\end{array}$ & $\begin{array}{l}0.079^{* * *} \\
(81.76)\end{array}$ & $\begin{array}{l}0.051^{* * *} \\
(70.96)\end{array}$ \\
\hline $\begin{array}{l}\text { OK+Texaco } \\
\text { (Aug 1994) }\end{array}$ & $\begin{array}{l}-0.005 \\
(-1.37)\end{array}$ & $\begin{array}{l}-0.006 \\
(-0.97)\end{array}$ & $\begin{array}{l}-0.003^{*} \\
(-1.93)\end{array}$ & $\begin{array}{l}-0.005 \\
(-0.61)\end{array}$ & $\begin{array}{l}-0.003 \\
(-1.53)\end{array}$ & $\begin{array}{r}0.001 \\
(0.35)\end{array}$ & $\begin{array}{l}-0.002 \\
(-1.15)\end{array}$ & $\begin{array}{l}-0.001 \\
(-1.37)\end{array}$ \\
\hline $\begin{array}{l}\text { OK-Preem } \\
\text { (Oct 1995) }\end{array}$ & $\begin{array}{c}-0.010^{* * *} \\
(-2.71)\end{array}$ & $\begin{array}{c}0.002 \\
(0.26)\end{array}$ & $\begin{array}{l}-0.004^{*} \\
(-1.82)\end{array}$ & $\begin{array}{c}0.009 \\
(0.76)\end{array}$ & $\begin{array}{l}-0.003 \\
(-1.17)\end{array}$ & $\begin{array}{r}0.007 \\
(1.61)\end{array}$ & $\begin{array}{l}-0.003^{* *} \\
(-2.00)\end{array}$ & $\begin{array}{c}-0.002 \\
(-2.71)\end{array}$ \\
\hline $\mathrm{R} 2$ & 0.77 & 0.83 & 0.62 & 0.82 & 0.70 & 0.82 & 0.12 & 0.877 \\
\hline $\mathrm{F}$ & 90.91 & 43.81 & 14.55 & 34.86 & 20.28 & 37.70 & 2.23 & 30.91 \\
\hline Number of observations & 153 & 153 & 153 & 153 & 153 & 153 & 153 & 153 \\
\hline
\end{tabular}




\subsection{Robustness}

We checked our results in a number of ways. First, we experimented with a host of additional demand specifications, which did not qualitatively change our results. Further, we also re-estimated demand before and after the introduction of VAT, and verified that this procedure - as suggested in Section 3.3 - did not change our direct estimates of conduct from (16). Using pooled and separate demand estimates, we also checked the influence on our estimates on conduct of the elasticity adjusted Lerner index when including the preVAT benchmark period in estimating (18). Controlling for VAT, the results in Table 4 were not affected. However, the influence of concentration on conduct is over-estimated if not controlling for VAT.

Furthermore, we also estimated the demand equation (1) and the supply equation (4) simultaneously following Bettendorf and Verboven (2000). ${ }^{20}$ Using this procedure for the full sample period between 1985-2000, we could check (i) the consistency of our two-stage approach of separating demand and supply estimations, and (ii) in particular check our assumptions on marginal cost. Across demand specifications, we then found conduct to vary between 0.01 and 0.02 , which is lower than the estimations using the elasticity-adjusted Lerner index in (18), but roughly the same as the estimate of conduct when estimating (16) over the full sample period 1985-2000. ${ }^{21}$ We estimate a unobserved component of marginal cost of approximately 0.36 SEK per liter.

To further check our estimates, we calculated the VAT adjusted gross margin $P_{t}-$ $(1+\tau)\left[T_{A} X_{t}+P_{S P O T_{t}}\right]$, which is illustrated in Figure 3 as the vertical distance between the price $P_{t}$ and the (marginal cost measure) $(1+\tau)\left[T A X_{t}+P S P O T_{t}\right]$. Taking the average over the post-VAT benchmark and merger period, we calculate this to be 1.39 SEK. From (5),(6) and (15), we can also calculate a predicted VAT-adjusted gross margin

\footnotetext{
${ }^{20}$ As we are interested in examining the effect on conduct of multiple transactions occurring on the market, this approach was intractable for estimating the effect on conduct of the separate mergers, given the limited amount of data available.

21 The finding that the elasticity-adjusted Lerner index produces a higher value of conduct seems to be in line with the findings reported by Genovese and Mullins (1998).
} 
using the fact that:

$$
P_{t}-(1+\tau)\left[T A X_{t}+P S P O T_{t}\right]=(1+\tau) c_{0}+\theta \frac{P_{t}}{\epsilon\left(P_{t}\right)} .
$$

Inserting a conduct of $\theta=0.05$, which is roughly the average of the estimates from (16) and (18), assuming the unobserved component of marginal cost to be $c_{0}=0.40$ SEK, calculating the price elasticity $\epsilon\left(P_{t}\right)$ from the estimated linear demand (11), we can derive that the average predicted gross margin was 1.41 in the period after VAT was introduced in 1990. Thus, our estimates do quite well in predicting the data.

Figure 3 also gives an informal illustration of our results. Note that the VAT adjusted gross margin remains remarkably stable over the period from 1990 and hence, virtually unrelated to the variation in concentration implied by the investigated market transactions. While we do observe an increase in the gross margin after VAT was introduced in 1990, this cannot be attributed to increased concentration, since there was no such increase until three year later.

\section{Conclusions}

The empirical findings in this paper have implications for the assessment of collusion and collective dominance in merger control. The gasoline retail market formally satisfies the necessary conditions for tacit collusion, i.e. there are several possibilities of reaching a consensus agreement, detecting and punishing deviations and the barriers to entry are substantial.

The empirical analysis of several mergers during the period 1993 to 1999 highlights the empirical problems associated with predicting the collusive effects of mergers. We generally find the effects of mergers to be small. In addition, the evidence is mixed and seems to depend on many factors.

First, the results depend on the specification of the demand function. A correct specification of the demand function can, therefore, be of vital importance for a correct assessment. Second, we find weak evidence of conduct to be related to market concentration 
which could, for instance, depend on insignificant market power at the present level of concentration or efficiencies off-setting the anti-competitive effects of increased concentration.

We conclude that the most obvious and important observable measure of structural change caused by a merger (i.e. a change in a concentration index such as HHI) has little explanatory power in the assessment of collective dominance and coordinated effects. Predicting the coordinated effects of mergers "out-of-sample" is, therefore, extremely difficult and associated with great uncertainty. This conclusion is also supported by the finding that there is significant variation in post-merger effects from one merger to the other.

\section{References}

[1] Baker, J. B., 2002, "Mavericks, Mergers, and Exclusion: Proving Coordinated Competitive Effects Under the Antitrust Laws", New York University Law Review, Vol. 77, No 1 (April), pp. 135-203

[2] Bettendorf, L. and Verboven, F., 2000, "Incomplete Transmission of Coffee Bean Prices: Evidence from The Netherlands", European Review of Agricultural Economics, Vol.27, No.1, pp.1-16.

[3] Borenstein, S. and Shepard, A., 1996, "Dynamic Pricing in Retail Gasoline Markets", RAND Journal of Economics, Vol. 27, No.3, pp. 429-451.

[4] Clay, K. and Troesken, W., 2003, "Further Tests of Statistic Oligopoly Models: Whiskey 1882-1898", The Journal of Industrial Economics, Vol.51, Issue 2, pp. 151166

[5] Coleman, M. and Scheffman, D.T., 2003, "Quantitative Analyses of Potential Competitive Effects from A Merger", George Mason Law Review, forthcoming

[6] Coleman, M., Meyer D. W. and Scheffman, D.T., 2003, "Empirical Analyses of Potential Competitive Effects of a Horizontal Merger: The FTC's Cruise Ships Merger Investigation", Review of Industrial Organization, forthcoming 
[7] Compte, O., Jenny, F. and Rey, P., 2002, "Capacity Constraints, Mergers and Collusion." European Economic Review, Vol.46, No.1, pp.1-29

[8] Cort, K.S., 1999, "Conduct Parameters and the Measurement of Market Power", Journal of Econometrics, Vol.88, pp.227-250

[9] Dick, Andrew R., 1996, "Identifying Contracts, Combinations and Conspiracies in Restraint of Trade", Managerial and Decision Economics, Vol. 17, pp.203-216.

[10] Dick, Andrew. R., 2002, "Coordinated Interaction: Pre-Merger Constraints and Post-Merger Effects", mimeo, US Department of Justice, available at http://www.crai.com/Agenda/Dick.pdf

[11] Genovese, D. and Mullin, W.P., 1998, "Testing Static Oligopoly Models: Conduct and Cost in the Sugar Industry, 1890-1914", RAND Journal of Economics, Vol. 29, No.2, pp. $355-377$.

[12] Jacquemin A. and Slade M., 1989, "Cartels, Collusion, and Horizontal Merger", in Handbook of Industrial Organization, Vol I, edited by R Schmalensee and R D Willig, Elsevier Science Publishers B.V., pp 415-473

[13] James, C.A., 2002, "Rediscovering Coordinated Effects", mimeo, US Department of Justice

[14] Kolasky, J.,W., 2002, "Coordinated Effects in Merger Review: From Dead Frenchmen to Beautiful Minds and Mavericks", mimeo, US Department of Justice

[15] Nevo, A., 2001, "Measuring Market Power in the Ready-to-Eat Cereal Industry.", Econometrica, Vol.69, No.2, pp. 307-342.

[16] Pitofsky, R, 2001, "FTC Merger Enforcement in the Gasoline Industry, Statement before The Committee on Commerce, Science, and Transportation Subcommittee on Consumer Affairs", Foreign Commerce, and Tourism United States Senate, April 25, 2001, downloaded from http://www.ftc.gov 
[17] Slade, M.E., 1987, "Intrafirm rivalry in a repeated game: an empirical test of tacit collusion", Journal of Industrial Economics, Vol. 35, pp. 499-516

[18] Slade, M.E., 1992, "Vancouver's Gasoline-Price Wars: An Empirical Exercise in Uncovering Supergame Strategies", The Review of Economic Studies, Vol. 59:2 (Apr), pp. $257-276$

[19] Slade, M.E., 2003, "Beer and the Tie: Did Divestiture of Brewer-owned Public Houses Lead to Higher Beer Prices?", Journal of Industrial Economics, Vol. 108, Issue 448, pp. 565-602

[20] Symeonidis, G., 2003, "In Which Industries Is Collusion More Likely? Evidence From UK", The Journal of Industrial Economics, Vol. 51, No.1, pp.45-73

[21] Willig, R.D., (1991), "Merger Analysis, industrial Organization Theory, and Merger Guidelines," Brookings Papers on Economic Activity - Microeconomics, pp 281-332 


\section{A Summary statistics}

Table A.1: Summary statistics .

\begin{tabular}{ll}
\hline Market statistics & 2001 \\
\hline \hline Value (SEK million) & 51579 \\
Value (US\$m) & 4998 \\
Share of GDP & $2.3 \%$ \\
Share of private consumption & $4.7 \%$ \\
Cars in traffic & 4018500 \\
\hline
\end{tabular}

Table A.2: Summary of raw data.

\begin{tabular}{lcccccc}
\hline & Number Obs. & Mean & Std. Dev. & Min & Max & Source: \\
\hline \hline $\begin{array}{l}\text { Gasoline prices } \\
\left.\text { (PRICE, } P_{t}\right)\end{array}$ & 275 & 6.18 & 2.15 & 2.71 & 10.54 & $\begin{array}{l}\text { SCB, SPI } \\
\text { Oanda }\end{array}$ \\
$\begin{array}{l}\text { Private cars in traffic, } \\
\text { (CARS) }\end{array}$ & 275 & 1.14 & 0.11 & 0.93 & 1.34 & SCB \\
$\begin{array}{l}\text { Cons per capita, } \\
\text { (CONS) }\end{array}$ & 275 & 0.31 & .011 & .012 & .049 & SCB \\
$\begin{array}{l}\text { Private cars deregistered } \\
\text { (CARSD) }\end{array}$ & 275 & 0.97 & 0.15 & 0.66 & 1.37 & SCB \\
$\begin{array}{l}\text { Oilprice, } \\
\text { (POIL) }\end{array}$ & 275 & 4.55 & 1.70 & 1.93 & 7.54 & $\begin{array}{l}\text { SCB, SPI, Swedish } \\
\text { Direct taxes, } \\
\text { (TAX) }\end{array}$ \\
$\begin{array}{l}\text { Gasoline input prices, } \\
\text { (PINPUT) }\end{array}$ & 275 & 3.13 & 1.10 & 1.27 & 4.62 & SPI \\
\hline
\end{tabular}

Note: Platts classification for gasoline prices is "prem unl CIF NWE Cargoes". 